Supplement of Solid Earth, 12, 2087-2107, 2021

https://doi.org/10.5194/se-12-2087-2021-supplement

(c) Author(s) 2021. CC BY 4.0 License.

(c) (i)

solit Eant EGGU

Supplement of

\title{
Coupled dynamics and evolution of primordial and recycled heterogene- ity in Earth's lower mantle
}

Anna Johanna Pia Gülcher et al.

Correspondence to: Anna J. P. Gülcher (anna.guelcher@erdw.ethz.ch)

The copyright of individual parts of the supplement might differ from the article licence. 
Content of the Supplement

\section{S1. Additional figures and explanations for modelled mantle composition}

S1.1 Initial layering set-up

S1.2 Density profiles of modelled materials

S1.3 Visualisation and heterogeneity detection

\section{S2 Resolution tests}

S3 Plate-like behavior in numerical models

S4 Additional numerical models (test model suite)

S4.1 Description of chemical layering regime (II)

S4.2 Rationale for main runs

S4.3 Fitting ambient mantle composition

S5. Summary of numerical experiments 


\section{S1 Additional figures and explanations for modelled mantle composition}

\section{S1.1 Initial layering set-up}

The various initial conditions of chemical layering used for this study are illustrated in Figure S1. All models include a thick, primordial layer $\left((\mathrm{Mg}, \mathrm{Fe}) \mathrm{SiO}_{3}\right.$-enhanced $)$ in the lower mantle underlying a $\approx$ pyrolitic upper layer. For cases in the main model suite (panel a), this layer thickness varies between $1564-1844 \mathrm{~km}$, according the results from the test model suite (panel b), in which the primordial layer for all cases and expands from the CMB to the top of the lower mantle (660 km depth). The results of this test suite are presented in Supplement S4). Finally, selected cases are initialised as a three-layered system (panel c), in which a thin FeO-rich layer is imposed just above the CMB (150, 200, or $250 \mathrm{~km}$-thick). Such an additional dense layer is motivated by recent magma ocean crystallization studies that suggest the co-existence of iron-rich bridgmanite with Fe-poor bridgmanite cumulates (Wang et al., 2021). The imposed material properties of the FeO-rich layer are the same as for basalt (i.e. intrinsically dense, see Fig. S2).
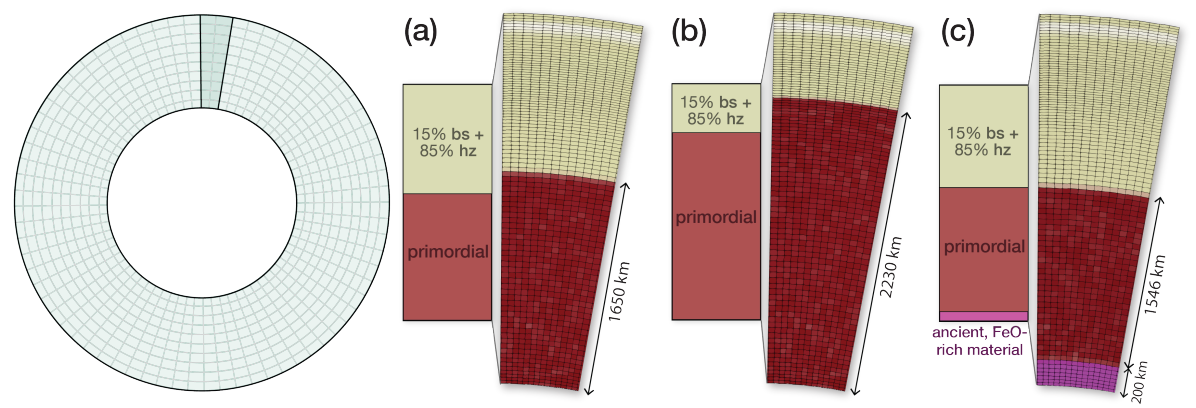

Figure S1. Schematic sketch and actual model domain showing the various chemical layering set-ups used for different model suites. The modelled domain is discretised in $512 \times 95$ cells, and resolved by over 1.2 million markers. Reference model $\left(\lambda_{\text {prim }}=100 ; B=0.28\right)$ for a $)$ Main model suite b) Test model suite c) 3-Layered set-up. Here, the primordial layer is moved away from the CMB and its thickness $D_{\text {prim }}$ is recalculated to have an equal volume of primordial material initialised as in case (a).

\section{S1.2 Density profiles of modelled materials}

The density profiles of the relevant mantle materials in this study are plotted in Figure S2. The profiles of harzburgite and basaltic materials are consistent with those from $\mathrm{Xu}$ et al. (2008), while that of primordial material is parametrised to be consistent with a rocky material with a $(\mathrm{Mg}+\mathrm{Fe}) / \mathrm{Si}$ ratio of $\approx 1.0$, such as bridgmanite. In the upper mantle, it fits the density profile of a solid solution of $40 \%$ basalt and $60 \%$ harzburgite from Xu et al. (2008). As in (Gülcher et al., 2020), we further impose a relatively higher bulk modulus in the lower mantle for primordial material (230 Gpa) than for other lower-mantle materials $(210 \mathrm{GPa})$. Such higher bulk modulus is motivated by high-pressure experimental studies of bridgmanite (Wolf et al., 2015), and it affects the lower-mantle density gradient for primordial material (Fig. S2). Linearly fitting this primordial density profile to those obtained by experimental studies of pure $\mathrm{MgSiO}_{3}$ bridgmanite (Tange et al., 2012) and $\mathrm{Mg}_{0.87} \mathrm{Fe}_{0.13} \mathrm{SiO}_{3}$ 
(a)

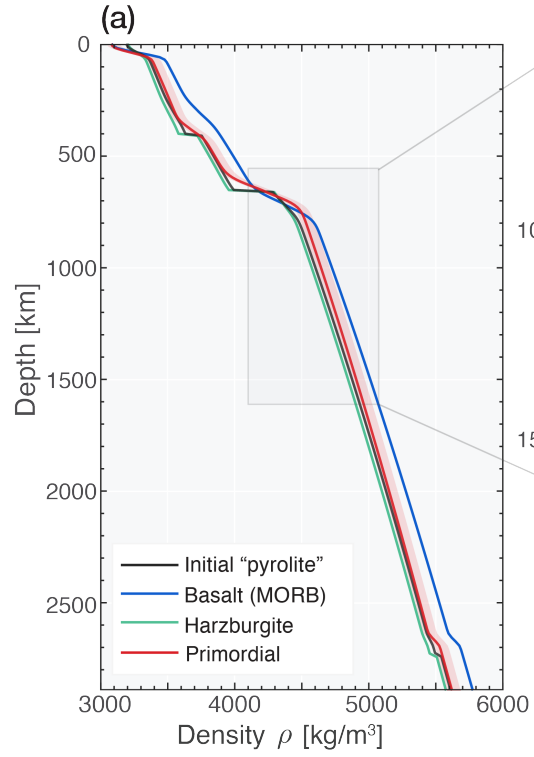

(b)

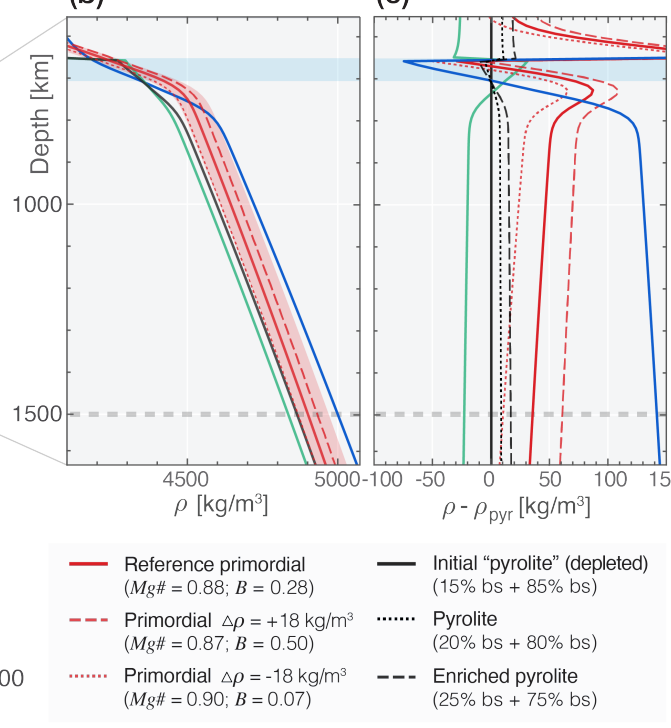

Figure S2. Density profiles for mantle materials used in the models. a) Profiles for harzburgite (black), basalt (light blue), initial "pyrolite" (dark blue), and primordial material (red). b) Zoom-in on mid-mantle depths. Basaltic material is less dense than pyrolite in the depth range of the blue shaded area (mantle-transition zone). The buoyancy number $B$ is calculated at $1500 \mathrm{~km}$ depth (grey dotted line). c) Relative density contrasts with depth for mantle materials relative to that of the initial "pyrolitic" material. The red solid line stands for the primordial material in our reference model, and the dashed and dotted red lines represent primordial materials with a buoyancy shift $\triangle B= \pm 0.21$. The initial "pyrolite" material is plotted as the black solid line, which is lightly depleted to that of present-day pyrolite ( $20 \%$ bs and $80 \% \mathrm{hz}$, black dotted line). A more enriched pyrolite composition ( $25 \% \mathrm{bs}$ and $75 \% \mathrm{hz})$ is plotted as a black dashed line.

bridgmanite (Wolf et al., 2015) materials at mid-mantle depths (1500 km), we estimate that our reference primordial material can be interpreted as corresponding to $\mathrm{Mg}_{0.88} \mathrm{Fe}_{0.12} \mathrm{SiO}_{2}$, or any other material with a similar density profile. To explore the effects of buoyancy ratio $B$, we shift the density profile of primordial material throughout the mantle with steps of $6 \mathrm{~kg} / \mathrm{m}^{3}$ between $-18 \mathrm{~kg} / \mathrm{m}^{3}$ and $+24 \mathrm{~kg} / \mathrm{m}^{3}$. Thereby, $B$ in the models varies between 0.07 and 0.57 , which corresponds to an approximate $\mathrm{Mg} \#$ of to primordial material ranging from $0.9-0.86$.

\section{S1.3 Visualisation and heterogeneity detection}

While the composition of an individual tracer is either primordial or a projection on a one-dimensional axis between basalt and harzburgite, that of a grid cell can contain all three possible end-members. The cell composition is therefore visualised with a two-dimensional triangular colour map (Fig. S3a). Two types of lower-mantle chemical heterogeneity are detected in the experiments: primordial $\left(\chi_{\text {prim }}^{\mathrm{LM}}\right)$ and recycled oceanic crust $\left(\chi_{\mathrm{ROC}}^{\mathrm{LM}}\right)$. We define $\chi_{\mathrm{prim}}^{\mathrm{LM}}$ and $\chi_{\mathrm{ROC}}^{\mathrm{LM}}$ as the relative volumes of the lower mantle with fractions of primordial material of $f_{\text {prim }}>0.6$ and of ROC of $f_{\mathrm{bs}}>0.6$, respectively (Fig. S3b). 

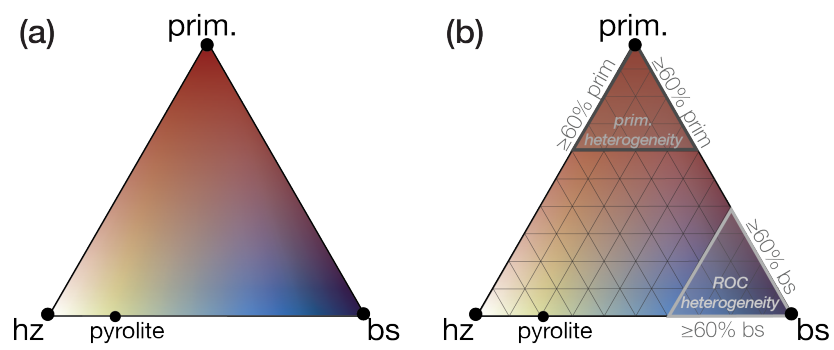

Figure S3. a) colour scale used in this study to show composition on a grid level, that can consist of harzburgite, basalt and primordial material; b) visualisation of the chemical heterogeneity detection. Primordial heterogeneity $\chi_{\text {prim }}^{\mathrm{LM}}$ is defined as: $f_{\text {prim }}>0.6$; ROC heterogeneity $\chi_{\mathrm{ROC}}^{\mathrm{LM}}$ is defined as: $f_{\mathrm{bs}}>0.6$.

\section{S2 Resolution tests}

We performed resolution tests for selected models $\left(M_{\mathrm{dD} 30}, M_{\mathrm{dD} 100}\right.$, and $\left.M_{\mathrm{dD} 300}\right)$ to test the sensitivity of our mantle heterogeneity predictions to grid resolution and tracer density. In these tests, we did not observe any qualitative changes in the overall dynamics of our models or the predicted mantle evolution: all models with different resolution but the same physical parameters show similar styles of final mantle heterogeneity preservation. There is no uniform, directional trend in convective vigour $\left(v_{\mathrm{RMS}}\right)$ seen between the models of different resolution (Fig. S4a), although for cases $M_{\mathrm{dD} 30}$ and $M_{\mathrm{dD} 300}, v_{\mathrm{RMS}}$ is moderately decreased $(\approx 10 \%)$ for a $2 \times 2$ times higher resolution than that used for our main models.

For models with a twice higher tracer density than our main suite of models, changes in terms of final heterogeneity ( $\chi_{\text {prim }}^{\mathrm{LM}}$ and $\left.\chi_{\mathrm{bs}}^{\mathrm{LM}}\right), v_{\mathrm{RMS}}$, and other proxies of mantle dynamics, are negligible (Fig. S4). These small changes are likely related to a slightly different initial condition that is related to thermal and compositional noise carried at the tracers. For example, the amplitude of the initial compositional noise at the grid level should be effectively smaller for high versus low resolution, as the interpolation from tracers to the grid averages over this random noise.

In contrast, the grid resolution does slightly affect the final quantities of final primordial and ROC heterogeneity in the lower mantle, expressed as $\chi_{\mathrm{bs}}^{\mathrm{LM}}$ and $\chi_{\text {prim }}^{\mathrm{LM}}$ (see Fig. S4b-c). $\chi_{\mathrm{bs}}^{\mathrm{LM}}$ reflects the integrated entrainment and segregation of basalt over time, as basaltic materials are entrained by the convecting mantle from thermochemical piles, but they also keep on being added to the piles by segregation of basalt from harzburgite. For a higher grid resolution, small-scale basaltic heterogeneity is better resolved, and thus segregation is slightly more efficient in regions with low viscosity, such as the PPV layer. Also, a better resolved boundary between ROC piles and the ambient mantle leads to less artificial entrainment (e.g. Sobouti et al., 2001; Zhong and Hager, 2003). Overall, $\chi_{b s}^{\mathrm{LM}}$ slightly increases with increasing resolution (Fig. S4b). In our models, primordial material is entrained by the convecting mantle at the margins of blobs with high primordial-material content, $\chi_{\text {prim }}^{\mathrm{LM}}$ thereby reflects the integrated entrainment of primordial material in the lower mantle over time. $\chi_{\text {prim }}^{\mathrm{LM}}$ increases somewhat more substantially with increasing grid resolution: for the three cases explored, $\chi_{\text {prim }}^{\mathrm{LM}}$ increases by $\approx 20 \%$ from cases with a resolution of $512 \times 96$ to high-resolution cases with $1024 \times 192$ grid cells (Fig. S4c). 
(a)

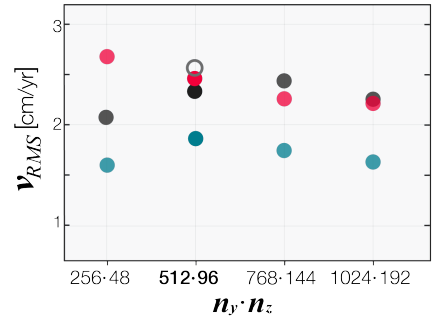

(c)

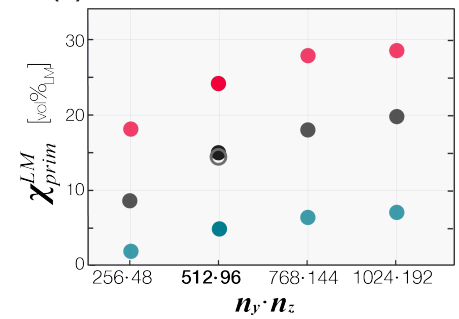

(b)

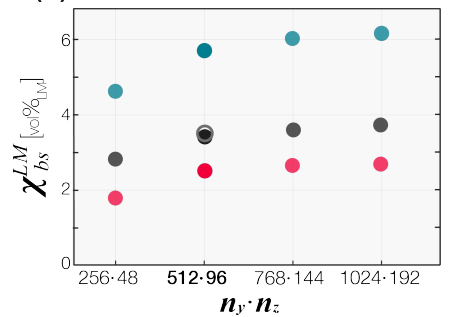

$$
\begin{aligned}
& \text { - } M_{d D} 30 \\
& \text { - } M_{d D} 100 \\
& \text { ○ } M_{d D} 100\left(200 \% N_{\text {tracers }}\right) \\
& \text { - } M_{d D} 300
\end{aligned}
$$

Figure S4. Outcomes of the resolution tests with models $M_{\mathrm{dD} 30}$ (green), $M_{\mathrm{dD} 100}$ (black), and $M_{\mathrm{dD} 300}$ (red). The horizontal axis indicates the different grid resolutions $\left(n_{\mathrm{y}} \times n_{\mathrm{z}}\right)$ explored. The main models of this study have a resolution of $512 \times 96$ grid cells. The vertical axis differs between panels: (a) the root-mean-square velocity of the modelled mantles, averaged over 4.0 and 5.0 Gyr model time; (b) the fraction of ROC heterogeneity $\left(\chi_{\mathrm{ROC}}^{\mathrm{LM}}\right.$ : reservoirs with $f_{\mathrm{ROC}} \geq 0.6$ ) or $(\mathbf{c})$ primordial heterogeneity $\left(\chi_{\text {prim }}^{\mathrm{LM}}\right.$ : reservoirs with $f_{\text {prim }} \geq 0.6$ ) in the lower mantle, averaged over 4.25-4.5 Gyr model time.

Overall, our results suggest that basalt segregation and primordial material preservation is slightly underestimated in our model suite with a resolution of $512 \times 96$, mostly because entrainment is overestimated at lower resolution (as found in e.g. Tackley and King, 2003; Tackley, 2011). Indeed, prior studies have demonstrated the requirement of sufficiently high numerical resolution to better quantify entrainment of intrinsically dense materials by mantle plumes (van Keken et al., 1997; Zhong and Hager, 2003). Along these lines, it is not surprising that entrainment is resolution-dependent, but we have to make a practical choice here to limit computational costs, and allow the exploration of a vast parameter space. Overall, this resolutions test demonstrates that our estimates of lower-mantle heterogeneity preservation, especially in terms of of primordial material, remain conservative.

\section{S3 Plate-like behavior in numerical models}

As in Tackley (2000), we measure plateness $P$ (the degree to which surface deformation is localized) and mobility $M$ (the extend to which the lithosphere is able to move). Plateness is defined as:

$P=1-f_{80} / f_{80, \text { iso }}$

were $f_{80}$ corresponds to the proportion of the surface that localises $80 \%$ of the total deformation and the value of $f_{80 \text {,iso }}$ for an isoviscous model (about 0.6 for models with Rayleigh number $>10^{6}$, Tackley, 2000). The mobility $M$ is the ratio of the 
root mean-square (RMS) surface velocity to RMS velocity in the whole domain. Plate-like behaviour occurs when $P$ is close to 1 and $M$ is close to or larger than 1 (Tackley, 2000). In Figure S5, the temporal evolution of plateness $P$ and mobility $M$ is plotted for a representative model for each identified mantle heterogeneity style. The models correspond to those discussed in the main text. Many of the "partial heterogeneity preservation" models (regime $I I I$ ) display plate tectonic behaviour after the onset of whole-mantle convection (i.e., after the compositional overturn). 
(a) Viscous blobs (III.B)

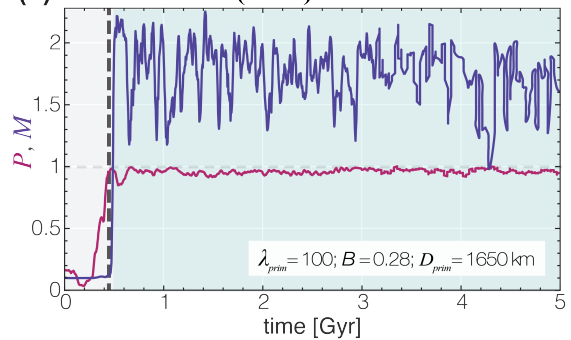

(c) "Marble cake" mantle (III.M)

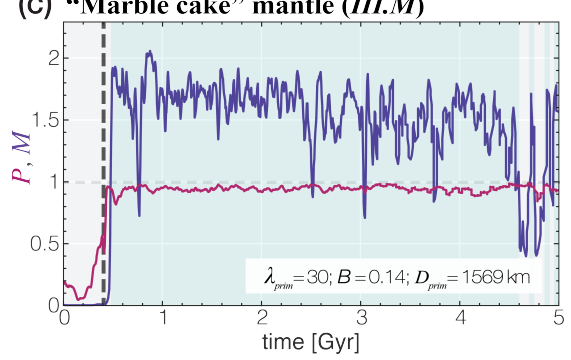

(e) Metastable "piles" (III.P)

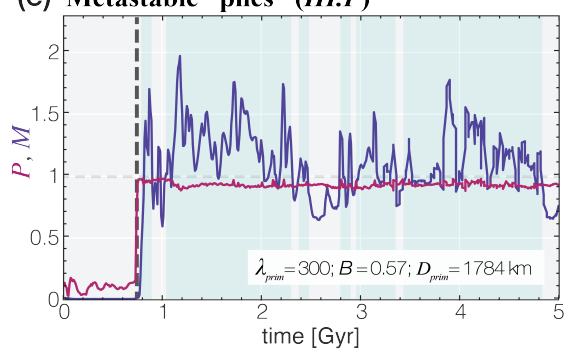

(g) Post-overturn ROC layering (II.R $)$

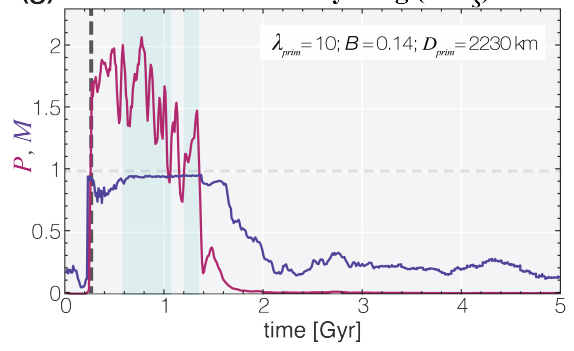

plate-tectonic behavior (b) Viscous blobs (III.B)

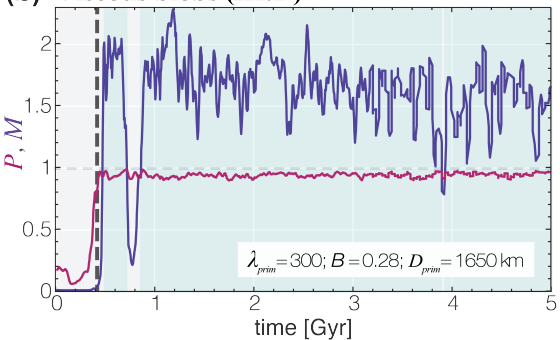

(d) Diffuse domains (III.D)

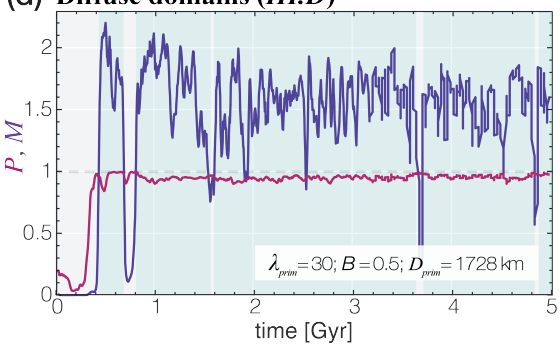

(f) Prim. layer with topography (II.T)

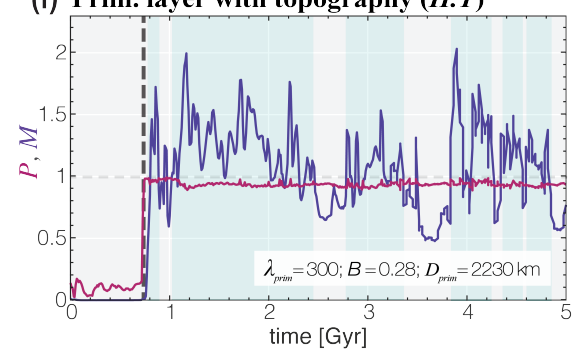

(h) Post-overturn ROC layering (II.R $)$

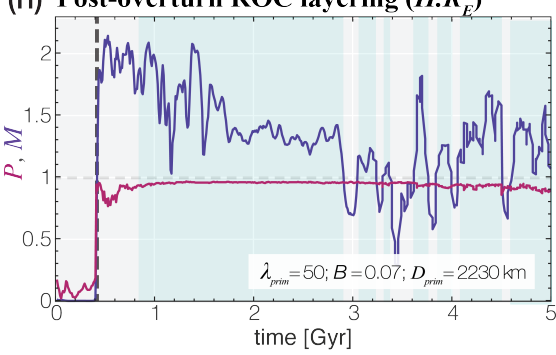

mobility $M$

plateness $\boldsymbol{P}$

Figure S5. Plateness $P$ and mobility $M$ through time for the selected cases of each geodynamic regime identified the models. The black dotted line indicates the onset of the compositional overturn. Plate-tectonic behavior (in line with Tackley, 2000) intervals are marked in shaded blue. 


\section{S4 Additional numerical models (test model suite)}

A test model suite was run in a parameter space of $\lambda_{\text {prim }}=[10,500]$ and $B=[0.07,0.78]$ with a fixed primordial layer thickness

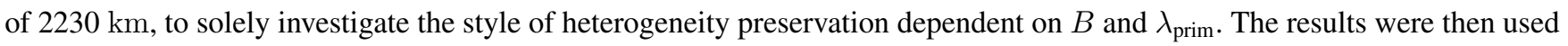
as an input for the main set of models (see Section S4.3). In this test model suite, a wide range of chemical heterogeneity preservation styles was observed, as is summarized in Fig. S7. Many of these include the regimes described in the main text, with the addition of two styles of chemical layering (regime $I I$ ):

\section{S4.1 Description of chemical layering regime (II)}

Models within regime II display strong compositional layering of the mantle after 4.5 Gyr of model evolution. These models span a wide range of compositional structures as well as tectonic styles across two subregimes (see Fig. S7):

\section{S4.1.1 Primordial layer with topography (II.T)}

For large $B(>0.7)$, the initial layered configuration is preserved throughout model evolution. Both mantle down- and upwellings developing from the thermal boundary layers at the base of the lithosphere and the CMB, respectively, are deflected at the compositional interface. Subsequently, persistent double-layered convection develops with variable topography sustained at the interface as supported by flow in both layers. While primordial material largely remains confined to the lowermost mantle, thin tendrils of ROC are entrained into the lower layer and reach the lowermost mantle (Fig. S6a). Ultimately, primordial heterogeneity occupies about $60 \mathrm{v} \%$ of the lower mantle, in contrast to a mere $0.2 \mathrm{v} \%$ of ROC heterogeneity. The tectonic style is characterized by dominant mobile-lid behaviour $(M>1)$ with short intervals of low mobility $(M<1$, Fig. S5). This regime is similar to that described in Kellogg et al. (1999) and in Gülcher et al. (2020).

\section{S4.1.2 Post-overturn ROC layering (II.R $R_{S}$ and II. $\left.R_{E}\right)$}

For near-zero $B$ and $\lambda_{\text {prim }} \leq 100$, models display (semi-)stable chemical stratification of the mantle with a stagnant-lid (II.RS to mobile-lid $\left(I I . R_{E}\right)$ tectonic style. In contrast to the previously described subregime, the chemical layering is formed after a large-scale overturn and is characterized by a thick layer of ROC at the base of the mantle ( $>7 \mathrm{v} \%)$. Initially, doublelayered convection is sustained for several 100s Myr as both weak lower-mantle upwellings and upper-mantle downwellings are deflected at the compositional interface in the mid mantle. However, progressive heating and cooling of the lower and upper mantles, respectively, promotes a whole-mantle overturn at $0.9 \mathrm{Gyr}$. This thick ROC layer forms because much of the primordial material reaches the upper mantle during the overturn, and is subsequently processed by extensive near-surface melting. Consequently, a large volume of basaltic crust forms that soon sinks to the lower mantle. The intrinsic high density of this ROC (Fig. S2a) precludes any further entrainment by upwelling plumes. A small amount of primordial material $(<4$ $\mathrm{v} \%$ ) is preserved in the uppermost lower mantle, either as a thin diffuse primordial-material enhanced region (regime II.R $R_{S}$ $\lambda_{\text {prim }}=10$, Fig. S6b) or small coherent blobs (regime II. $R_{E}, \lambda_{\text {prim }} \geq 30$, Fig. S6c). Subsequent model evolution is characterized by chemical stratification with a ROC layer that mostly fully covers the CMB and small-scale convection within this layer, as it is heated from below. The upper mantle is strongly depleted (harzburgitic), preventing any significant further melting. In 
(a) Prim. layer with topography (II.T) $\lambda_{\text {prim }}=100 ; B=0.78 ; D_{\text {prim }}=2230 \mathrm{~km}$
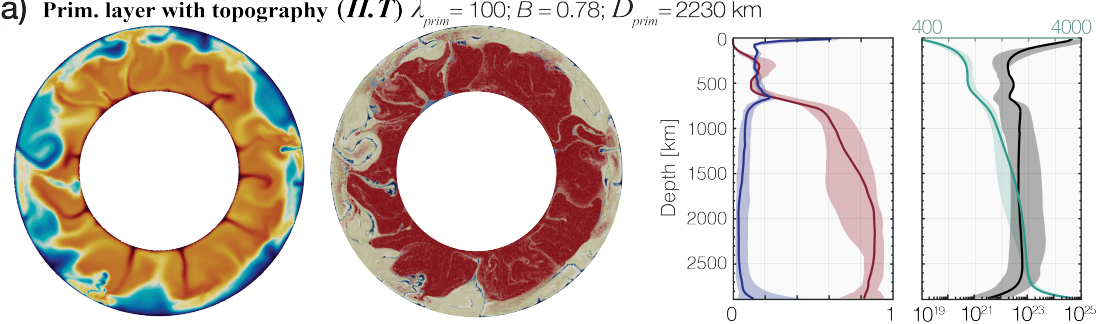

(b) Stable ROC layering $\left(\boldsymbol{I I . \boldsymbol { R } _ { S }}\right) \lambda_{\text {prim }}=10 ; B=0.14 ; D_{\text {prim }}=2230 \mathrm{~km}$
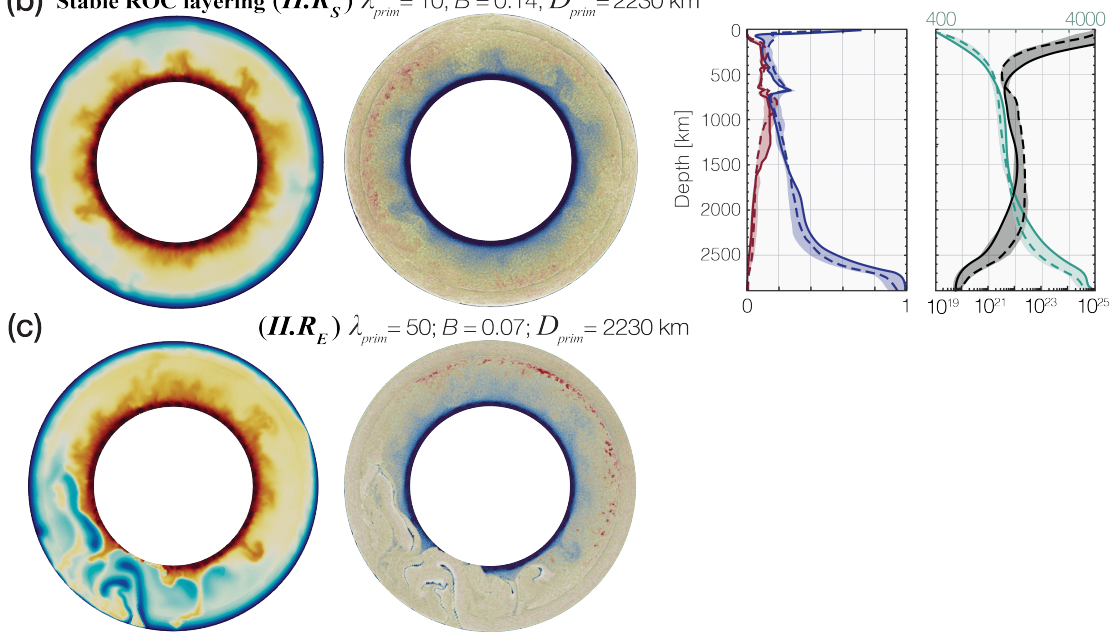

$\left(\boldsymbol{I} . \boldsymbol{R}_{E}\right) \lambda_{\text {prim }}=50 ; B=0.07 ; D_{p r i m}=2230 \mathrm{~km}$
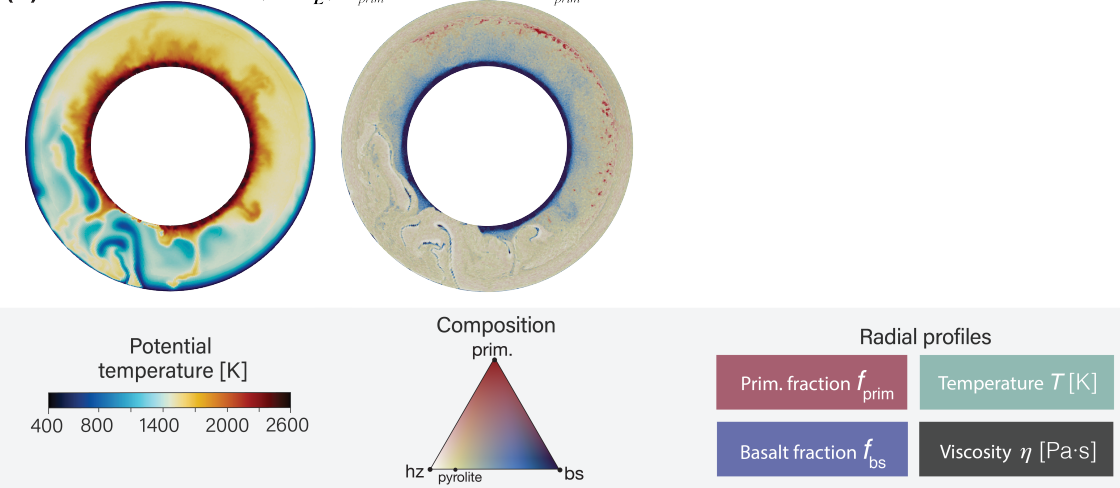

Figure S6. Left: Mantle sections of potential temperature (left) and composition (centre) for the two styles within regime $I I(\mathrm{chemical}$ layering) at $4.5 \mathrm{Gyr}$ model time. $\lambda_{\text {prim }}$ and $B$ as labelled. (right) corresponding profiles of primordial fraction, basaltic fraction, temperature and viscosity. These profiles are radially averaged and time-averaged (4.25-4.5 Gyr). The shaded region indicates the range for all models in any given subregime. Dashed lines refer to the case shown in panel (c).

this stratified mantle, convective vigour remains low. The radially averaged temperature and viscosity profiles (Figs. S6b,c) highlight the layering of the mantle, e.g., by showing an intermediate thermal boundary layer. For $\lambda_{\text {prim }} \geq 30$ (regime II. $R_{E}$ ), plates sporadically sink into the lower-mantle, as mobility $M$ fluctuates over time (Fig. S5c). For $\lambda_{\text {prim }} \leq 10$ (regime II.RS), the tectonic style is characterized by a stagnant lid (low $P$ and $M$, Fig. S5b).

\section{S4.2 Rationale for main runs}

The final bulk composition of the ambient (non-primordial) mantle $\left(f_{\mathrm{bs}, \text { amb }}^{\mathrm{final}}\right)$ and related, the final amount of ROC heterogeneity that may form from the ambient mantle, depends on the fraction of primordial material that is processed in the upper mantle (melting) ( $\chi_{\text {prim }}^{\text {pres }}$, see eq. (3) and Methods). In the test models discussed here, $f_{\mathrm{bs}, \text { amb }}^{\text {final }}$ attains highly variable values, depending 


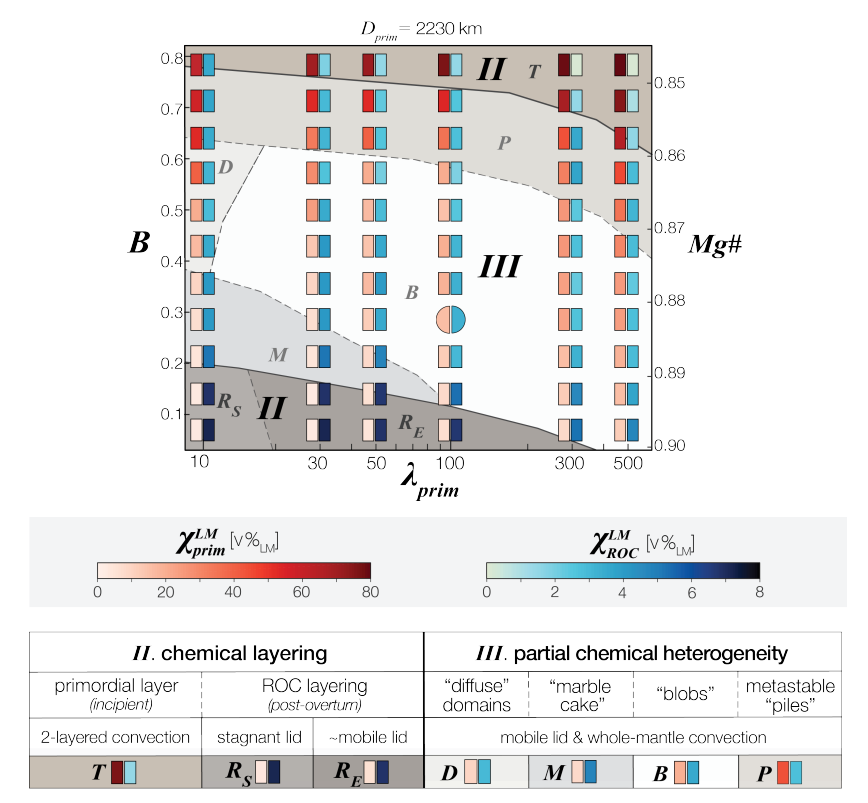

Figure S7. Summary of key results as a function of physical parameters of primordial material for the test model suite, in which the initialised primordial layer thickness is constant across the models $\left(D_{\text {prim }}=2230 \mathrm{~km}\right)$. The vertical axis represents the initial buoyancy ratio $B$, defined at $1500 \mathrm{~km}$ depth (Methods and Supplement S1.3), or the corresponding Mg\# of primordial material. The horizontal axis gives the viscosity contrast $\lambda_{\text {prim }}$ between primordial and pyrolitic material in the lower mantle. The fraction of primordial heterogeneity $\left(\chi_{\text {prim }}^{\mathrm{LM}}\right.$, red) and ROC $\left(\chi_{\mathrm{ROC}}^{\mathrm{LM}}\right.$, blue) in the lower mantle are averaged between 4.25 and 4.5 Myr model time (for definitions, see Supplement S1.3). In these models, regime $(I I)$ is newly identified, in which models display chemical stratification as a primordial layer with topography (" $\left.T^{\prime \prime}\right)$ or post-overturn ROC layering (" $R_{S} " ;$ " $\left.R_{E} "\right)$.

on $\chi_{\text {prim }}^{\text {pres }}$ (see Table S1). Models that display initial layering preservation (regime II.T), have an ambient mantle that is, relative to other models in this suite, most depleted as little primordial material is processed $\left(f_{\mathrm{bs}, \mathrm{fmb}}^{\mathrm{fina}}<0.25\right)$. For all other regimes, $B \leq 0.71)$, moderate-to-much primordial material processing causes variably high $f_{\mathrm{bs}, \mathrm{amb}}^{\mathrm{fina}}(0.27-0.33)$, i.e., much higher than commonly assumed for Earth (0.2-0.25). The rationale for the main model suite is to have ambient mantle compositions (and therefore the potential of ROC heterogeneity formation) comparable with one another, and we systematically vary the initial primordial material volume (to lower values) to obtain a similar ambient mantle composition between the models.

\section{S4.3 Fitting ambient mantle composition}

In order to compute $D_{\text {prim }}$ for the main numerical experiments, we rewrite eq. (3) within the following assumptions. First, we assume that the final volume of primordial material mixing depends primarily on the preservation factor of primordial material and initial volume of primordial material:

$V_{\text {prim,molten }}^{\mathrm{final}}=V_{\text {prim }}^{\mathrm{ini}}-V_{\text {prim }}^{\mathrm{final}}=\left(1-\chi_{\text {prim }}^{\mathrm{pres}}\right) \cdot V_{\text {prim }}^{\mathrm{ini}}$ 
with preserved primordial volume fraction $\chi_{\text {prim }}^{\text {pres }}\left(=\frac{V_{\text {prim }}^{\text {final }}}{V_{\text {prim }}^{\text {in }}}\right)$. Secondly, for simplicity, we assume that the preservation factor $\chi_{\text {prim }}^{\text {pres }}$ remains roughly constant for a given set of physical parameters of primordial material (viscosity contrast $\lambda_{\text {prim }}$ and intrinsic buoyancy number $B$ ). Moreover, each experiment (set of $\lambda_{\text {prim }}$ and $B$ ), we set $\chi_{\text {prim }}^{\text {pres }}$ equal to the resulting final primordial heterogeneity volume ( $\chi_{\text {prim }}^{\mathrm{LM}}$ in Table $\mathrm{S} 2$ ) fraction from the same experiment in the test model suite. With these assumptions, we rewrite eq. (3) as:

$f_{\mathrm{bs,amb}}^{\text {final }}=\frac{f_{\mathrm{bs,amb}}^{\mathrm{ini}} \cdot\left(V_{\text {mantle }}-V_{\mathrm{prim}}^{\mathrm{ini}}\right)+c_{\mathrm{bs}, \text { prim }} \cdot\left(1-\chi_{\mathrm{prim}}^{\mathrm{pres}}\right) \cdot V_{\text {prim }}^{\mathrm{ini}}}{V_{\text {mantle }}-\chi_{\text {prim }}^{\text {pres }} \cdot V_{\text {prim }}^{\text {ini }}}$

Alternatively, we can make $V_{\text {prim }}^{\text {ini }}$ dependent on $f_{\mathrm{bs}, \text { amb }}^{\text {final }}$ by rewriting eq. (S3):

$f_{\mathrm{bs}, \mathrm{amb}}^{\mathrm{final}} \cdot V_{\mathrm{mantle}}-f_{\mathrm{bs}, \mathrm{amb}}^{\mathrm{final}} \cdot \chi_{\mathrm{prim}}^{\mathrm{pres}} \cdot V_{\mathrm{prim}}^{\mathrm{ini}}=f_{\mathrm{bs}, \mathrm{amb}}^{\mathrm{ini}} \cdot V_{\mathrm{mantle}}-f_{\mathrm{bs}, \mathrm{amb}}^{\mathrm{ini}} \cdot V_{\mathrm{prim}}^{\mathrm{ini}}+c_{\mathrm{bs}, \mathrm{prim}} \cdot\left(1-\chi_{\mathrm{prim}}^{\text {pres }}\right) \cdot V_{\mathrm{prim}}^{\mathrm{ini}}$

$f_{\mathrm{bs}, \mathrm{amb}}^{\mathrm{ini}} \cdot V_{\mathrm{prim}}^{\mathrm{ini}}-f_{\mathrm{bs}, \mathrm{amb}}^{\mathrm{final}} \cdot \chi_{\mathrm{prim}}^{\mathrm{pres}} \cdot V_{\mathrm{prim}}^{\mathrm{ini}}-c_{\mathrm{bs}, \mathrm{prim}} \cdot\left(1-\chi_{\mathrm{prim}}^{\mathrm{pres}}\right) \cdot V_{\mathrm{prim}}^{\mathrm{ini}}=f_{\mathrm{bs}, \mathrm{amb}}^{\mathrm{ini}} \cdot V_{\mathrm{mantle}}-f_{\mathrm{bs}, \mathrm{amb}}^{\mathrm{final}} \cdot V_{\mathrm{mantle}}$

$V_{\mathrm{prim}}^{\mathrm{ini}}\left(f_{\mathrm{bs}, \mathrm{ambt}}^{\mathrm{ini}}-f_{\mathrm{bs}, \mathrm{amb}}^{\mathrm{final}} \cdot \chi_{\mathrm{prim}}^{\mathrm{pres}}-c_{\mathrm{bs}, \mathrm{prim}} \cdot\left(1-\chi_{\mathrm{prim}}^{\mathrm{pres}}\right)\right)=V_{\text {mantle }}\left(f_{\mathrm{bs}, \mathrm{amb}}^{\mathrm{ini}}-f_{\mathrm{bs}, \mathrm{amb}}^{\mathrm{final}}\right)$

leading to the expression for $V_{\text {prim }}^{\text {ini }}$ :

$V_{\text {prim }}^{\text {ini }}=V_{\text {mantle }} \frac{f_{\mathrm{bs}, \text { amb }}^{\text {final }}-f_{\mathrm{bs}, \text { amb }}^{\text {ini }}}{c_{\mathrm{bs}, \text { prim }}^{\text {pres }} \cdot\left(1-\chi_{\mathrm{prim}}^{\text {pres }}\right)+\chi_{\mathrm{prim}}^{\text {pres }} \cdot f_{\mathrm{bs,amb}}^{\text {final }}-f_{\mathrm{bs,amb}}^{\text {ini }}}$

We use eq. (S7) and set the target ambient mantle composition on $f_{\mathrm{bs}, \text { amb }}^{\text {inal }}=0.25$ to find $V_{\text {prim }}^{\text {ini }}$ (and hence $D_{\text {prim}}$ ) for each case. Note that since we use spherical annulus geometry, all volumes scale as in 3D spherical geometry (Hernlund and Tackley, 2008).

Following this approach, all main models display a final ambient mantle composition of $f_{\mathrm{bs}, \text { amb }}^{\text {final }}=0.24-0.26$ (Table S1) after 4.5 Gyr model time. This outcome demonstrates that the above assumptions are valid within reasonable margin. 


\section{S5 Summary of numerical experiments}

Table S1: Model parameter summary and output quantities of models in the model suite discussed in the main text, averaged between 4.25 and $4.5 \mathrm{Gyr}$ of model evolution. All models have a different $D_{\text {prim }}$, see text. Plateness $P$ and mobility $M$ from Tackley (2000). * Denotes the reference model.

\begin{tabular}{|c|c|c|c|c|c|c|c|c|c|c|c|c|c|}
\hline Model & $\lambda_{\text {prim }}$ & $B(M g \#)$ & $\begin{array}{l}D_{\text {prim }} \\
{[\mathrm{km}]}\end{array}$ & $\begin{array}{c}t_{\mathrm{ot}} \\
{[\mathrm{Gyr}]}\end{array}$ & $P$ & $M$ & $\begin{array}{c}T_{\text {mean }} \\
{[\mathrm{K}]}\end{array}$ & $\begin{array}{c}\eta_{\mathrm{av}} \\
{[\mathrm{Pa} \cdot \mathrm{s}]}\end{array}$ & $f_{\mathrm{bs}, \mathrm{amb}}^{\text {final }}$ & $\begin{array}{c}\chi_{\text {prim }}^{\text {pres }} \\
{\left[\mathrm{v} \%_{\text {prim }}^{\text {ini }}\right]}\end{array}$ & $\begin{array}{c}\chi_{\mathrm{prim}}^{\mathrm{LM}} \\
{\left[\mathrm{v} \%_{\mathrm{LM}}\right]}\end{array}$ & $\begin{array}{c}\chi_{\mathrm{ROC}}^{\mathrm{LM}} \\
{\left[\mathrm{v} \%_{\mathrm{LM}}\right]}\end{array}$ & regime \\
\hline$M_{10 \mathrm{aD}}$ & 10 & $0.07(0.90)$ & 1568 & 0.28 & 0.93 & 1.49 & 1935 & $2.1 \cdot 10^{24}$ & 0.26 & 1.7 & 1.0 & 6.9 & III.M \\
\hline$M_{10 \mathrm{bD}}$ & 10 & $0.14(0.89)$ & 1568 & 0.30 & 0.95 & 1.49 & 1984 & $8.1 \cdot 10^{23}$ & 0.26 & 2.5 & 1.5 & 5.7 & III.M \\
\hline$M_{10 \mathrm{cD}}$ & 10 & $0.21(0.89)$ & 1580 & 0.32 & 0.92 & 1.52 & 2011 & $1.3 \cdot 10^{24}$ & 0.25 & 2.6 & 1.6 & 6.1 & III.M \\
\hline$M_{10 \mathrm{dD}}$ & 10 & $0.28(0.88)$ & 1582 & 0.32 & 0.95 & 1.43 & 2021 & $1.1 \cdot 10^{24}$ & 0.25 & 2.1 & 1.3 & 7.1 & III.M \\
\hline$M_{10 \mathrm{eD}}$ & 10 & $0.35(0.88)$ & 1583 & 0.34 & 0.97 & 1.40 & 2087 & $9.3 \cdot 10^{23}$ & 0.25 & 3.0 & 1.8 & 6.0 & III.D \\
\hline$M_{10 \mathrm{fD}}$ & 10 & $0.42(0.87)$ & 1586 & 0.35 & 0.94 & 1.13 & 2115 & $8.5 \cdot 10^{23}$ & 0.25 & 3.3 & 2.0 & 5.7 & III.D \\
\hline$M_{10 \mathrm{gD}}$ & 10 & $0.50(0.87)$ & 1603 & 0.33 & 0.97 & 1.24 & 2186 & $9.3 \cdot 10^{23}$ & 0.26 & 3.9 & 2.4 & 4.2 & III.D \\
\hline$M_{10 \mathrm{hD}}$ & 10 & $0.57(0.86)$ & 1615 & 0.34 & 0.97 & 1.3 & 2218 & $7.2 \cdot 10^{23}$ & 0.26 & 6.8 & 4.2 & 3.4 & III.D \\
\hline$M_{30 \mathrm{aD}}$ & 30 & $0.07(0.90)$ & 1574 & 0.51 & 0.94 & 1.38 & 1999 & $6.9 \cdot 10^{23}$ & 0.25 & 1.8 & 1.1 & 4.0 & III.M \\
\hline$M_{30 \mathrm{bD}}$ & 30 & $0.14(0.89)$ & 1569 & 0.52 & 0.94 & 1.42 & 2063 & $5.7 \cdot 10^{23}$ & 0.25 & 1.7 & 1.0 & 4.5 & III.M \\
\hline$M_{30 \mathrm{cD}}$ & 30 & $0.21(0.89)$ & 1583 & 0.6 & 0.94 & 1.56 & 2063 & $9.0 \cdot 10^{23}$ & 0.25 & 6.6 & 4.0 & 5.3 & III.B \\
\hline$M_{30 \mathrm{dD}}$ & 30 & $0.28(0.88)$ & 1603 & 0.54 & 0.93 & 1.61 & 2090 & $8.7 \cdot 10^{23}$ & 0.25 & 8.1 & 5.0 & 5.8 & III.B \\
\hline$M_{30 \mathrm{eD}}$ & 30 & $0.35(0.88)$ & 1627 & 0.57 & 0.95 & 1.51 & 2150 & $8.2 \cdot 10^{23}$ & 0.25 & 3.8 & 2.4 & 5.5 & III.B \\
\hline$M_{30 \mathrm{fD}}$ & 30 & $0.42(0.87)$ & 1656 & 0.68 & 0.96 & 1.57 & 2202 & $5.8 \cdot 10^{23}$ & 0.25 & 4.9 & 3.2 & 4.2 & III.D \\
\hline$M_{30 \mathrm{gD}}$ & 30 & $0.50(0.87)$ & 1728 & 0.85 & 0.94 & 1.43 & 2214 & $4.6 \cdot 10^{23}$ & 0.26 & 5.2 & 3.7 & 2.8 & III.D \\
\hline$M_{30 \mathrm{hD}}$ & 30 & $0.57(0.86)$ & 1702 & 0.87 & 0.95 & 1.36 & 2194 & $5.5 \cdot 10^{23}$ & 0.25 & 7.5 & 5.2 & 3.8 & III.D \\
\hline$M_{50 \mathrm{aD}}$ & 50 & $0.07(0.90)$ & 1583 & 0.54 & 0.93 & 1.5 & 2034 & $5.6 \cdot 10^{23}$ & 0.25 & 3.7 & 2.3 & 3.6 & III.M \\
\hline$M_{50 \mathrm{bD}}$ & 50 & $0.14(0.89)$ & 1594 & 0.53 & 0.93 & 1.59 & 2085 & $5.1 \cdot 10^{23}$ & 0.25 & 7.7 & 4.8 & 5.3 & III.B \\
\hline$M_{50 \mathrm{cD}}$ & 50 & $0.21(0.89)$ & 1607 & 0.55 & 0.94 & 1.3 & 2110 & $7.3 \cdot 10^{23}$ & 0.25 & 13.0 & 8.1 & 4.8 & III.B \\
\hline$M_{50 \mathrm{dD}}$ & 50 & $0.28(0.88)$ & 1617 & 0.58 & 0.96 & 1.5 & 2130 & $7.6 \cdot 10^{23}$ & 0.25 & 7.6 & 4.7 & 5.8 & III.B \\
\hline$M_{50 \mathrm{eD}}$ & 50 & $0.35(0.88)$ & 1695 & 0.64 & 0.93 & 1.5 & 2171 & $5.5 \cdot 10^{23}$ & 0.25 & 13.2 & 8.8 & 5.5 & III.B \\
\hline$M_{50 \mathrm{fD}}$ & 50 & $0.42(0.87)$ & 1656 & 0.72 & 0.95 & 1.37 & 2210 & $5.1 \cdot 10^{23}$ & 0.25 & 12.8 & 8.3 & 3.4 & III.D \\
\hline$M_{50 \mathrm{gD}}$ & 50 & $0.50(0.87)$ & 1728 & 1 & 0.95 & 1.54 & 2192 & $4.7 \cdot 10^{23}$ & 0.25 & 15.1 & 10.4 & 2.0 & III.D \\
\hline$M_{50 \mathrm{hD}}$ & 50 & $0.57(0.86)$ & 1710 & 1.05 & 0.96 & 1.4 & 2180 & $6.7 \cdot 10^{23}$ & 0.25 & 18 & 12.1 & 2.2 & III.D \\
\hline$M_{100 \mathrm{aD}}$ & 100 & $0.07(0.90)$ & 1590 & 0.6 & 0.93 & 1.43 & 2036 & $6.1 \cdot 10^{23}$ & 0.25 & 9.2 & 5.6 & 4.0 & III.B \\
\hline$M_{100 \mathrm{bD}}$ & 100 & $0.14(0.89)$ & 1615 & 0.58 & 0.95 & 1.51 & 2105 & $6.3 \cdot 10^{23}$ & 0.24 & 16.1 & 10.1 & 4.0 & III.B \\
\hline$M_{100 \mathrm{cD}}$ & 100 & $0.21(0.89)$ & 1619 & 0.62 & 0.96 & 1.6 & 2161 & $5.7 \cdot 10^{23}$ & 0.24 & 23.7 & 14.9 & 4.4 & III.B \\
\hline $\boldsymbol{M}_{100 \mathrm{dD}} *$ & 100 & $0.28(0.88)$ & 1650 & 0.68 & 0.95 & 1.3 & 2212 & $6.2 \cdot 10^{23}$ & 0.24 & 23.7 & 15.3 & 3. & III.B \\
\hline$M_{100 \mathrm{eD}}$ & 100 & $0.35(0.88)$ & 1706 & 0.74 & 0.94 & 1.44 & 2222 & $4.9 \cdot 10^{23}$ & 0.25 & 15.8 & 10.7 & 2.5 & III.B \\
\hline$M_{100 \mathrm{fD}}$ & 100 & $0.42(0.87)$ & 1717 & 0.85 & 0.93 & 1.51 & 2204 & $4.1 \cdot 10^{23}$ & 0.25 & 18.6 & 12.7 & 2.2 & III.B \\
\hline$M_{100 \mathrm{gD}}$ & 100 & $0.50(0.87)$ & 1657 & 1.4 & 0.95 & 1.54 & 2189 & $5.4 \cdot 10^{23}$ & 0.24 & 32.2 & 20.9 & 1.3 & III.B \\
\hline$M_{100 \mathrm{hD}}$ & 100 & $0.57(0.86)$ & 1670 & 1.34 & 0.96 & 1.44 & 2101 & $7.8 \cdot 10^{23}$ & 0.25 & 34.1 & 22.3 & 1.2 & III.D \\
\hline$M_{300 \mathrm{aD}}$ & 300 & $0.07(0.90)$ & 1617 & 0.68 & 0.94 & 1.19 & 2105 & $5.6 \cdot 10^{23}$ & 0.25 & 13.3 & 8.3 & 3.0 & III.B \\
\hline$M_{300 \mathrm{cD}}$ & 300 & $0.21(0.89)$ & 1678 & 0.8 & 0.95 & 1.41 & 2185 & $6.4 \cdot 10^{23}$ & 0.24 & 35.6 & 23.5 & 3.1 & III.B \\
\hline$M_{300 \mathrm{dD}}$ & 300 & $0.28(0.88)$ & 1717 & 0.92 & 0.94 & 1.61 & 2194 & $6.1 \cdot 10^{23}$ & 0.24 & 35.5 & 24.2 & 2.5 & III.B \\
\hline$M_{300 \mathrm{eD}}$ & 300 & $0.35(0.88)$ & 1743 & 1.18 & 0.94 & 1.53 & 2167 & $4.2 \cdot 10^{23}$ & 0.24 & 35.3 & 24.6 & 2.0 & III.B \\
\hline$M_{300 \mathrm{fD}}$ & 300 & $0.42(0.87)$ & 1768 & 1.38 & 0.91 & 1.69 & 2105 & $5.6 \cdot 10^{23}$ & 0.25 & 32.1 & 22.8 & 1.3 & III.B \\
\hline
\end{tabular}




\begin{tabular}{|c|c|c|c|c|c|c|c|c|c|c|c|c|c|}
\hline$M_{300 \mathrm{gD}}$ & 300 & $0.50(0.87)$ & 1762 & 1.64 & 0.93 & 1.68 & 2025 & $6.1 \cdot 10^{23}$ & 0.24 & 36.2 & 25.6 & 1.4 & III.P \\
\hline$M_{300 \mathrm{hD}}$ & 300 & $0.57(0.86)$ & 1766 & 1.68 & 0.96 & 1.66 & 2052 & $7.5 \cdot 10^{23}$ & 0.26 & 43.3 & 32.6 & 1.3 & III.D \\
\hline$M_{500 \mathrm{aD}}$ & 500 & $0.07(0.90)$ & 1621 & 0.8 & 0.95 & 1.35 & 2068 & $6.3 \cdot 10^{23}$ & 0.25 & 12.3 & 7.7 & 3.5 & III.B \\
\hline$M_{500 \mathrm{bD}}$ & 500 & $0.14(0.89)$ & 1635 & 0.9 & 0.94 & 1.31 & 2127 & $5.7 \cdot 10^{23}$ & 0.24 & 25.3 & 16.1 & 2.7 & III.B \\
\hline$M_{500 \mathrm{cD}}$ & 500 & $0.21(0.89)$ & 1699 & 1.02 & 0.95 & 1.69 & 2180 & $5.3 \cdot 10^{23}$ & 0.23 & 41.7 & 28.0 & 2.8 & III.B \\
\hline$M_{500 \mathrm{dD}}$ & 500 & $0.28(0.88)$ & 1728 & 1.32 & 0.94 & 1.56 & 2172 & $6.3 \cdot 10^{23}$ & 0.24 & 38.9 & 26.8 & 2.5 & III.B \\
\hline$M_{500 \mathrm{eD}}$ & 500 & $0.35(0.88)$ & 1762 & 1.48 & 0.92 & 1.51 & 2150 & $4.9 \cdot 10^{23}$ & 0.24 & 37.5 & 26.5 & 1.8 & III.B \\
\hline$M_{500 \mathrm{fD}}$ & 500 & $0.42(0.87)$ & 1840 & 1.7 & 0.92 & 1.54 & 2084 & $5.7 \cdot 10^{23}$ & 0.25 & 38.5 & 29.0 & 2.3 & III.B \\
\hline$M_{500 \mathrm{gD}}$ & 500 & $0.50(0.87)$ & 1844 & 2 & 0.93 & 1.71 & 2012 & $9.1 \cdot 10^{23}$ & 0.24 & 44.0 & 33.2 & 1.4 & III.P \\
\hline$M_{500 \mathrm{hD}}$ & 500 & $0.57(0.86)$ & 1848 & 2.05 & 0.94 & 1.72 & 2032 & $8.8 \cdot 10^{23}$ & 0.25 & 48.0 & 36.1 & 1.1 & III.D \\
\hline$M_{50 \mathrm{dD}}^{B O}$ & 50 & $0.28(0.88)$ & 1539 & 0.55 & 0.95 & 1.62 & 2108 & $6.2 \cdot 10^{23}$ & 0.30 & 42 & 26.3 & 4.7 & III.B \\
\hline$M_{50 \mathrm{dD}}^{B 1}$ & 50 & $0.28(0.88)$ & 1514 & 0.57 & 0.94 & 1.44 & 2059 & $1.2 \cdot 10^{24}$ & 0.30 & 37.7 & 23.7 & 6.7 & III.B \\
\hline$M_{100 \mathrm{dD}}^{B O}$ & 100 & $0.28(0.88)$ & 1571 & 0.70 & 0.94 & 1.52 & 2101 & $6.3 \cdot 10^{23}$ & 0.30 & 41.5 & 27.0 & 4.1 & III.B \\
\hline$M_{100 \mathrm{dD}}^{B 1}$ & 100 & $0.28(0.88)$ & 1546 & 0.72 & 0.95 & 1.64 & 2038 & $1.1 \cdot 10^{24}$ & 0.30 & 43.4 & 28.2 & 6.3 & III.B \\
\hline$M_{100 \mathrm{dD}}^{B 2}$ & 100 & $0.28(0.88)$ & 1521 & 0.76 & 0.92 & 1.80 & 2039 & $1.5 \cdot 10^{24}$ & 0.30 & 40 & 26.1 & 8.7 & III.B \\
\hline
\end{tabular}

${ }^{\mathrm{B} 0-2}$ stands for additional ancient $\mathrm{FeO}$-rich ancient layer on top of the $\mathrm{CMB}$, with layer thickness $150\left({ }^{\mathrm{B} 0}\right), 200\left({ }^{\mathrm{B} 1}\right)$ and $250\left({ }^{\mathrm{B} 2}\right) \mathrm{km}$, respectively. 
Table S2: Model parameter summary and output quantities, averaged between 4.25 and $4.5 \mathrm{Gyr}$ of model evolution. Models in this table belong to the test model suite ( $D_{\text {prim }}$ fixed to $2230 \mathrm{~km}$, see Supplement S4). Plateness $P$ and mobility $M$ from Tackley (2000).

\begin{tabular}{|c|c|c|c|c|c|c|c|c|c|c|c|c|}
\hline Model & $\lambda_{\text {prim }}$ & $B(M g \#)$ & $\begin{array}{l}D_{\text {prim }} \\
{[\mathrm{km}]}\end{array}$ & $\begin{array}{c}t_{\mathrm{ot}} \\
{[\mathrm{Gyr}]}\end{array}$ & $P$ & $M$ & $\begin{array}{c}T_{\text {mean }} \\
{[\mathrm{K}]}\end{array}$ & $\begin{array}{c}\eta_{\mathrm{av}} \\
{[\mathrm{Pa} \cdot \mathrm{s}]}\end{array}$ & $f_{\mathrm{bs}, \mathrm{amb}}^{\mathrm{final}}$ & $\begin{array}{c}\chi_{\text {prim }}^{\mathrm{LM}} \\
{[\mathrm{v} \% \mathrm{LM}]}\end{array}$ & $\begin{array}{c}\chi_{\mathrm{ROC}}^{\mathrm{LM}} \\
{[\mathrm{v} \% \mathrm{LM}]}\end{array}$ & regime \\
\hline$M_{10 \mathrm{a}}$ & 10 & $0.07(0.9)$ & 2230 & 0.24 & 0.25 & 0.01 & 1975 & $7.0 \cdot 10^{24}$ & 0.32 & 0.0 & 11.2 & II.R $R_{S}$ \\
\hline$M_{10 \mathrm{~b}}$ & 10 & $0.14(0.89)$ & 2230 & 0.24 & 0.27 & 0.01 & 1967 & $6.9 \cdot 10^{24}$ & 0.32 & 0.1 & 10.5 & II. $R_{S}$ \\
\hline$M_{10 \mathrm{c}}$ & 10 & $0.21(0.89)$ & 2230 & 0.25 & 0.96 & 1.35 & 1963 & $9.8 \cdot 10^{23}$ & 0.31 & 1.8 & 6.4 & III.M \\
\hline$M_{10 \mathrm{~d}}$ & 10 & $0.28(0.88)$ & 2230 & 0.27 & 0.96 & 1.31 & 2061 & $9.0 \cdot 10^{23}$ & 0.31 & 2.1 & 5.2 & III.M \\
\hline$M_{10 \mathrm{e}}$ & 10 & $0.35(0.88)$ & 2230 & 0.27 & 0.94 & 1,52 & 2084 & $5.6 \cdot 10^{23}$ & 0.30 & 2.2 & 5.3 & III.M \\
\hline$M_{10 \mathrm{f}}$ & 10 & $0.42(0.87)$ & 2230 & 0.28 & 0.92 & 1.18 & 2133 & $7.9 \cdot 10^{23}$ & 0.29 & 2.6 & 5.8 & III.D \\
\hline$M_{10 \mathrm{~g}}$ & 10 & $0.50(0.87)$ & 2230 & 0.38 & 0.93 & 1.51 & 2179 & $7.8 \cdot 10^{23}$ & 0.29 & 5.3 & 5.0 & III.D \\
\hline$M_{10 \mathrm{~h}}$ & 10 & $0.57(0.86)$ & 2230 & 0.4 & 0.92 & 1.46 & 2205 & $6.5 \cdot 10^{23}$ & 0.28 & 7.0 & 4.6 & III.D \\
\hline$M_{10 \mathrm{i}}$ & 10 & $0.64(0.86)$ & 2230 & 0.88 & 0.91 & 1.25 & 2184 & $6.1 \cdot 10^{23}$ & 0.23 & 31.3 & 4.2 & III.P \\
\hline$M_{10 \mathrm{j}}$ & 10 & $0.71(0.85)$ & 2230 & 1.17 & 0.91 & 1.2 & 2190 & $4.9 \cdot 10^{23}$ & 0.24 & 33.6 & 3.6 & III.P \\
\hline$M_{10 \mathrm{k}}$ & 10 & $0.78(0.85)$ & 2230 & - & 0.92 & 0.98 & 2235 & $3.8 \cdot 10^{23}$ & 0.23 & 47.7 & 2.0 & II.T \\
\hline$M_{30 \mathrm{a}}$ & 30 & $0.07(0.9)$ & 2230 & 0.40 & 0.95 & 1.53 & 1930 & $3.2 \cdot 10^{24}$ & 0.32 & 1.1 & 9.3 & II. $\mathrm{R}_{\mathrm{E}}$ \\
\hline$M_{30 \mathrm{~b}}$ & 30 & $0.14(0.89)$ & 2230 & 0.40 & 0.95 & 1.22 & 1934 & $2 \cdot 10^{24}$ & 0.32 & 2.0 & 7.7 & II. $R_{\mathrm{E}}$ \\
\hline$M_{30 \mathrm{c}}$ & 30 & $0.21(0.89)$ & 2230 & 0.44 & 0.94 & 1.36 & 1992 & $6.4 \cdot 10^{23}$ & 0.32 & 2.8 & 4.8 & III.M \\
\hline$M_{30 \mathrm{~d}}$ & 30 & $0.28(0.88)$ & 2230 & 0.50 & 0.94 & 1.11 & 2078 & $6.7 \cdot 10^{23}$ & 0.31 & 5.0 & 4.2 & III.B \\
\hline$M_{30 \mathrm{e}}$ & 30 & $0.35(0.88)$ & 2230 & 0.65 & 0.97 & 1.33 & 2130 & $6.1 \cdot 10^{23}$ & 0.31 & 9.2 & 4.1 & III.B \\
\hline$M_{30 \mathrm{f}}$ & 30 & $0.42(0.87)$ & 2230 & 0.80 & 0.95 & 1.44 & 2150 & $5.5 \cdot 10^{23}$ & 0.31 & 13.3 & 3.9 & III.B \\
\hline$M_{30 \mathrm{~g}}$ & 30 & $0.50(0.87)$ & 2230 & 1.00 & 0.95 & 1.63 & 2177 & $4.7 \cdot 10^{23}$ & 0.30 & 23.8 & 3.4 & III.B \\
\hline$M_{30 \mathrm{~h}}$ & 30 & $0.57(0.86)$ & 2230 & 1.22 & 0.92 & 1.55 & 2180 & $4.2 \cdot 10^{23}$ & 0.30 & 28.5 & 2.2 & III.B \\
\hline$M_{30 \mathrm{i}}$ & 30 & $0.64(0.86)$ & 2230 & 1.48 & 0.94 & 1.40 & 2103 & $6.8 \cdot 10^{23}$ & 0.29 & 32.8 & 3.0 & III.P \\
\hline$M_{30 \mathrm{j}}$ & 30 & $0.71(0.85)$ & 2230 & 1.70 & 0.91 & 1.41 & 2110 & $1.4 \cdot 10^{24}$ & 0.26 & 56.0 & 3.0 & III.P \\
\hline$M_{30 \mathrm{k}}$ & 30 & $0.78(0.85)$ & 2230 & - & 0.92 & 1.04 & 2168 & $2.3 \cdot 10^{24}$ & 0.24 & 70.3 & 1.8 & II.T \\
\hline$M_{50 \mathrm{a}}$ & 50 & $0.07(0.90)$ & 2230 & 0.58 & 0.96 & 1.38 & 1955 & $3.4 \cdot 10^{24}$ & 0.32 & 1.9 & 7.7 & II. $R_{\mathrm{E}}$ \\
\hline$M_{50 \mathrm{~b}}$ & 50 & $0.14(0.89)$ & 2230 & 0.58 & 0.95 & 1.22 & 1936 & $2 \cdot 10^{24}$ & 0.31 & 4.7 & 7.0 & II. $R_{E}$ \\
\hline$M_{50 \mathrm{c}}$ & 50 & $0.21(0.89)$ & 2230 & 0.57 & 0.93 & 1.62 & 1941 & $1.2 \cdot 10^{24}$ & 0.31 & 4.8 & 6.1 & III.M \\
\hline$M_{50 \mathrm{~d}}$ & 50 & $0.28(0.88)$ & 2230 & 0.58 & 0.94 & 1.36 & 2116 & $5.5 \cdot 10^{23}$ & 0.31 & 11.3 & 3.5 & III.B \\
\hline$M_{50 \mathrm{e}}$ & 50 & $0.35(0.88)$ & 2230 & 0.62 & 0.96 & 1.31 & 2142 & $6.2 \cdot 10^{23}$ & 0.30 & 17.5 & 4.3 & III.B \\
\hline$M_{50 \mathrm{f}}$ & 50 & $0.42(0.87)$ & 2230 & 0.62 & 0.95 & 1.40 & 2177 & $5.5 \cdot 10^{23}$ & 0.31 & 14.3 & 3.3 & III.B \\
\hline$M_{50 \mathrm{~g}}$ & 50 & $0.50(0.87)$ & 2230 & 0.65 & 0.95 & 1.33 & 2127 & $5.3 \cdot 10^{23}$ & 0.30 & 18.2 & 2.9 & III.B \\
\hline$M_{50 \mathrm{~h}}$ & 50 & $0.57(0.86)$ & 2230 & 0.75 & 0.93 & 1.45 & 2132 & $4.6 \cdot 10^{23}$ & 0.30 & 20.6 & 2.0 & III.B \\
\hline$M_{50 \mathrm{i}}$ & 50 & $0.64(0.86)$ & 2230 & 1.20 & 0.92 & 1.47 & 2105 & $7.7 \cdot 10^{23}$ & 0.28 & 40.5 & 2.6 & III.P \\
\hline$M_{50 j}$ & 50 & $0.71(0.85)$ & 2230 & 1.45 & 0.91 & 1.11 & 2043 & $2.2 \cdot 10^{24}$ & 0.26 & 58.2 & 3.1 & III.P \\
\hline$M_{50 \mathrm{k}}$ & 50 & $0.78(0.85)$ & 2230 & - & 0.94 & 1.17 & 2155 & $2.4 \cdot 10^{24}$ & 0.23 & 74.5 & 1.7 & II.T \\
\hline$M_{100 \mathrm{a}}$ & 100 & $0.07(0.90)$ & 2230 & 0.89 & 0.94 & 1.43 & 1935 & $2.5 \cdot 10^{24}$ & 0.31 & 4.2 & 7.1 & II. $R_{\mathrm{E}}$ \\
\hline$M_{100 \mathrm{~b}}$ & 100 & $0.14(0.89)$ & 2230 & 0.90 & 0.96 & 1.20 & 1960 & $2.2 \cdot 10^{24}$ & 0.31 & 7.3 & 5.5 & III.B \\
\hline$M_{100 c}$ & 100 & $0.21(0.89)$ & 2230 & 0.90 & 0.94 & 1.36 & 2085 & $5.3 \cdot 10^{23}$ & 0.31 & 12.1 & 3.1 & III.B \\
\hline$M_{100 \mathrm{~d}}$ & 100 & $0.28(0.88)$ & 2230 & 0.90 & 0.94 & 1.45 & 2105 & $4.9 \cdot 10^{23}$ & 0.31 & 15.1 & 3.4 & III.B \\
\hline$M_{100 \mathrm{e}}$ & 100 & $0.35(0.88)$ & 2230 & 0.92 & 0.94 & 1.38 & 2142 & $5.1 \cdot 10^{23}$ & 0.30 & 18.6 & 3.3 & III.B \\
\hline$M_{100 \mathrm{f}}$ & 100 & $0.42(0.87)$ & 2230 & 0.95 & 0.95 & 1.75 & 2156 & $5.3 \cdot 10^{23}$ & 0.30 & 20.9 & 3.1 & III.B \\
\hline
\end{tabular}




\begin{tabular}{|c|c|c|c|c|c|c|c|c|c|c|c|c|}
\hline$M_{100 \mathrm{~g}}$ & 100 & $0.50(0.87)$ & 2230 & 1.07 & 0.93 & 1.50 & 2114 & $3.8 \cdot 10^{23}$ & 0.31 & 15.9 & 2.5 & III.B \\
\hline$M_{100 \mathrm{~h}}$ & 100 & $0.57(0.86)$ & 2230 & 1.20 & 0.94 & 1.43 & 2109 & $5.2 \cdot 10^{23}$ & 0.30 & 18.0 & 1.9 & III.B \\
\hline$M_{100 \mathrm{i}}$ & 100 & $0.64(0.86)$ & 2230 & 1.65 & 0.90 & 1.56 & 1957 & $1.5 \cdot 10^{24}$ & 0.29 & 34.9 & 3.5 & III.P \\
\hline$M_{100 \mathrm{j}}$ & 100 & $0.71(0.85)$ & 2230 & 1.70 & 0.93 & 1.41 & 2009 & $2.9 \cdot 10^{24}$ & 0.27 & 55.5 & 2.7 & III.P \\
\hline$M_{100 \mathrm{k}}$ & 100 & $0.78(0.85)$ & 2230 & - & 0.94 & 1.20 & 2152 & $2.6 \cdot 10^{24}$ & 0.22 & 78.5 & 1.5 & II.T \\
\hline$M_{300 \mathrm{a}}$ & 300 & $0.07(0.90)$ & 2230 & 1.48 & 0.92 & 1.56 & 1949 & $1.8 \cdot 10^{24}$ & 0.31 & 7.8 & 5.3 & III.B \\
\hline$M_{300 \mathrm{~b}}$ & 300 & $0.14(0.89)$ & 2230 & 1.48 & 0.96 & 1.37 & 1965 & $1.3 \cdot 10^{24}$ & 0.31 & 9.1 & 5.2 & III.B \\
\hline$M_{300 \mathrm{c}}$ & 300 & $0.21(0.89)$ & 2230 & 1.48 & 0.94 & 1.45 & 2048 & $6.4 \cdot 10^{23}$ & 0.31 & 15.3 & 3.2 & III.B \\
\hline$M_{300 \mathrm{~d}}$ & 300 & $0.28(0.88)$ & 2230 & 1.48 & 0.94 & 1.42 & 2178 & $5.7 \cdot 10^{23}$ & 0.30 & 22.9 & 2.5 & III.B \\
\hline$M_{300 \mathrm{e}}$ & 300 & $0.35(0.88)$ & 2230 & 1.50 & 0.95 & 1.69 & 2161 & $5.4 \cdot 10^{23}$ & 0.30 & 23.8 & 2.1 & III.B \\
\hline$M_{300 f}$ & 300 & $0.42(0.87)$ & 2230 & 1.50 & 0.92 & 1.57 & 2084 & $5 \cdot 10^{23}$ & 0.30 & 25.9 & 3.0 & III.B \\
\hline$M_{300 \mathrm{~g}}$ & 300 & $0.50(0.87)$ & 2230 & 1.50 & 0.90 & 1.48 & 2021 & $4.9 \cdot 10^{23}$ & 0.30 & 25.5 & 2.7 & III.B \\
\hline$M_{300 \mathrm{~h}}$ & 300 & $0.57(0.86)$ & 2230 & 1.52 & 0.90 & 1.59 & 1936 & $8.3 \cdot 10^{23}$ & 0.30 & 27.3 & 4.2 & III.P \\
\hline$M_{300 \mathrm{i}}$ & 300 & $0.64(0.86)$ & 2230 & 1.56 & 0.92 & 1.81 & 1935 & $3 \cdot 10^{24}$ & 0.28 & 43.0 & 3.8 & III.P \\
\hline$M_{300 \mathrm{j}}$ & 300 & $0.71(0.85)$ & 2230 & - & 0.92 & 1.19 & 2022 & $3.6 \cdot 10^{24}$ & 0.25 & 63.8 & 2.8 & II.T \\
\hline$M_{300 \mathrm{k}}$ & 300 & $0.78(0.85)$ & 2230 & - & 0.94 & 1.41 & 2177 & $3.9 \cdot 10^{24}$ & 0.21 & 85.0 & 0.66 & II.T \\
\hline$M_{500 a}$ & 500 & $0.07(0.90)$ & 2230 & 2.00 & 0.96 & 1.38 & 1935 & $2 \cdot 10^{4}$ & 0.31 & 8.6 & 5.6 & III.B \\
\hline$M_{500 \mathrm{~b}}$ & 500 & $0.14(0.89)$ & 2230 & 2.00 & 0.94 & 1.49 & 1979 & $9.6 \cdot 10^{23}$ & 0.31 & 10.1 & 3.8 & III.B \\
\hline$M_{500 \mathrm{c}}$ & 500 & $0.21(0.89)$ & 2230 & 2.00 & 0.93 & 1.41 & 2082 & $5.3 \cdot 10^{23}$ & 0.31 & 17.2 & 3.0 & III.B \\
\hline$M_{500 \mathrm{~d}}$ & 500 & $0.28(0.88)$ & 2230 & 2.00 & 0.93 & 1.28 & 2091 & $5.9 \cdot 10^{23}$ & 0.30 & 22.1 & 3.2 & III.B \\
\hline$M_{500 \mathrm{e}}$ & 500 & $0.35(0.88)$ & 2230 & 2.00 & 0.94 & 1.53 & 2139 & $5.4 \cdot 10^{23}$ & 0.30 & 24.7 & 2.5 & III.B \\
\hline$M_{500 \mathrm{f}}$ & 500 & $0.42(0.87)$ & 2230 & 2.03 & 0.92 & 1.57 & 2062 & $7.9 \cdot 10^{23}$ & 0.29 & 31.9 & 3.0 & III.B \\
\hline$M_{500 \mathrm{~g}}$ & 500 & $0.50(0.87)$ & 2230 & 2.05 & 0.93 & 1.51 & 2001 & $1 \cdot 10^{24}$ & 0.29 & 34.5 & 3.6 & III.P \\
\hline$M_{500 \mathrm{~h}}$ & 500 & $0.57(0.86)$ & 2230 & 2.10 & 0.91 & 1.64 & 1989 & $1.9 \cdot 10^{24}$ & 0.28 & 46.7 & 3.6 & III.P \\
\hline$M_{500 \mathrm{i}}$ & 500 & $0.64(0.86)$ & 2230 & 2.10 & 0.92 & 1.88 & 2061 & $3.6 \cdot 10^{24}$ & 0.24 & 69.7 & 1.6 & III.P \\
\hline$M_{500 \mathrm{j}}$ & 500 & $0.71(0.85)$ & 2230 & - & 0.94 & 1.59 & 1084 & $5 \cdot 10^{23}$ & 0.23 & 75.0 & 1.7 & II.T \\
\hline$M_{500 \mathrm{k}}$ & 500 & $0.78(0.85)$ & 2230 & - & 0.93 & 1.23 & 2167 & $5 \cdot 10^{23}$ & 0.20 & 86.2 & 0.5 & II.T \\
\hline
\end{tabular}




\section{References}

Gülcher, A. J., Gebhardt, D. J., Ballmer, M. D., and Tackley, P. J.: Variable dynamic styles of primordial heterogeneity preservation in the Earth's lower mantle, Earth and Planetary Sciences Letters, 536, https://doi.org/10.1016/j.epsl.2020.116160, 2020.

Hernlund, J. W. and Tackley, P. J.: Modeling mantle convection in the spherical annulus, Physics of the Earth and Planetary Interiors, 171, 48-54, https://doi.org/10.1016/j.pepi.2008.07.037, 2008.

Kellogg, L. H., Hager, B. H., and van der Hilst, R. D.: Compositional Stratification in the Deep mantle, An Introduction to Celestial Mechanics, 283, 1881-1884, www.sciencemag.org, 1999.

Sobouti, F., Ghods, A., and Arkani-Hamed, J.: On the advection of sharp material interfaces in geodynamic problems: Entrainment of the D" layer, Journal of Geodynamics, 31, 459-479, https://doi.org/10.1016/S0264-3707(01)00012-6, 2001.

Tackley, P. J.: Self-consistent generation of tectonic plates in time-dependent, three-dimensional mantle convection simulations 2 . strain weakening and asthenosphere, Geochemistry, Geophysics, Geosystems, 1, https://doi.org/10.1029/2000gc000036, 2000.

Tackley, P. J.: Living dead slabs in 3-D: The dynamics of compositionally-stratified slabs entering a " slab graveyard" above the core-mantle boundary, Physics of the Earth and Planetary Interiors, 188, 150-162, https://doi.org/10.1016/j.pepi.2011.04.013, http://dx.doi.org/10. 1016/j.pepi.2011.04.013, 2011.

Tackley, P. J. and King, S. D.: Testing the tracer ratio method for modeling active compositional fields in mantle convection simulations, Geochemistry, Geophysics, Geosystems, 4, 47 907, https://doi.org/10.1029/2001GC000214, 2003.

Tange, Y., Kuwayama, Y., Irifune, T., Funakoshi, K. I., and Ohishi, Y.: P-V-T equation of state of MgSiO3 perovskite based on the MgO pressure scale: A comprehensive reference for mineralogy of the lower mantle, Journal of Geophysical Research: Solid Earth, 117, 1-12, https://doi.org/10.1029/2011JB008988, 2012.

van Keken, P. E., King, S. D., Schmeling, H., Christensen, U. R., Neumeister, D., and Doin, M.-P.: A comparison of methods for the modeling of thermochemical convection, Journal of Geophysical Research: Solid Earth, 102, 22 477-22 495, https://doi.org/10.1029/97jb01353, 1997.

Wang, W., Liu, J., Zhu, F., Wu, Z., and Dorfman, S. M.: Formation of large low shear velocity provinces through the decomposition of oxidized mantle, Nature Communications, 12, https://doi.org/10.1038/s41467-021-22185-1, http://dx.doi.org/10.1038/s41467-021-22185-1, 2021.

Wolf, A. S., Jackson, J. M., Dera, P., and Prakapenka, V. B.: The thermal equation of state of ( Mg , Fe ) SiO 3 bridgmanite ( perovskite ) and implications for lower mantle structures, Journal of Geophysical Research B: Solid Earth, 120, 7460-7489, https://doi.org/10.1002/2015JB012108.Received, 2015.

Xu, W., Lithgow-Bertelloni, C., Stixrude, L., and Ritsema, J.: The effect of bulk composition and temperature on mantle seismic structure, Earth and Planetary Science Letters, 275, 70-79, https://doi.org/10.1016/j.eps1.2008.08.012, 2008.

Zhong, S. and Hager, B. H.: Entrainment of a dense layer by thermal plumes, Geophysical Journal International, 154, 666-676, https://doi.org/10.1046/j.1365-246X.2003.01988.x, 2003. 